\section{Dilatation of the Iris}

IN addition to the method of observation mentioned by $\mathrm{Mr}$. Ackroyd in his photometric proposal (NATURE, vol. xxi. p. 627) I may mention that the variations of the diameter of the pupil are very beautifully observed by a pair of punctures in a screen over the eye. In fact long ago I used this as a means of observing the absolute diameter of the pupil, subject to a small unexamined constant error.

By pricking a row of holes in a card at distances of $\cdot 06,{ }^{\circ} \mathrm{07}$, 08...25 inch, and placing this close over the eye, the diameter is observed by sliding the card until two of the holes are found at such a distance that their edges appear to touch. The opening of the other eye, or the slightest disturbance of light, produces an apparent alteration in the sizes of the disks of light, so that their edges recede or overlap; and a fresh pair of holes may be found showing the altered diameter of the pupil.

Thus (I) the extreme diameters of the pupil were found to be $\circ 7\left(\right.$ ? $\left.{ }^{\circ} 06\right)$ and $\cdot 25$ inch; (2) the diameter is rapidly variable at will, without any alteration of stimulus, even as much as from - 13 to 19 inch; (3) the sympathetic motion takes 4 or ' 5 second to be produced when the other eye is exposed to light. Many similar interesting questions may be examined by this simple instrument; for which purpose I inclose a sample card for editorial trial.

W. M. F. P.

\section{Comparative Curves in Terrestrial Magnetism}

Monsteur, -En séquence à la intéressante communication de Rev. S. J. Perry de l'Observatoire de Stonyhurst, je vous prie d'additioner les suivants renscignements sur la même perturbation magnétique de I 7 mars passé, d'après la courbe du déclinographe de l'Observatoire du Infant D. Luiz, à Lisbonne.

La différence entre le maximum et le premier minimum à 5h. 49,5m. G.M.T. est de $13^{\prime}, 9$ (un tiers du mouvement à Stonyhurst), et entre le même maximum et le $2^{\circ}$ minimum à

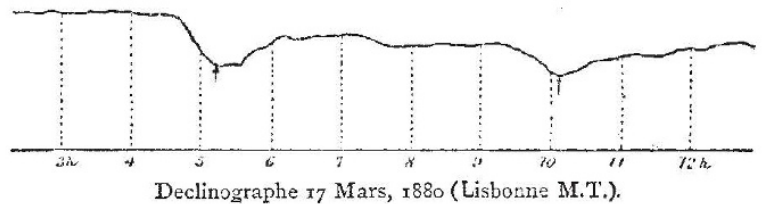

1oh, $45 \mathrm{~m}$. G.M.T. est un peu plus grande $16^{\prime}, 2$, le contraire qu'on voit à Vienne et Stonyhurst.

Il est digne aussi de remarque que le temps du I $^{\text {er }}$ minimum ne s'accorde avec le temps à Stonyhurst et Vienne, pendant que le temps du second est de parfait accord.

La longitude de cet Observatoire est $+36 \mathrm{~m}$. 35s. G. Je vous envoie la copie de la courbe.

Agréez, Monsieur, l'assurance de ma haute considération.

Lisbonne, 21 juin 1880

J. CAPELLO

\section{Effects of Ligbtning on Trees}

YOUR note in NATUkE, vol. xxii. p. 204, on the recent thunderstorm at Geneva induces me to send you a note on a tree struck by lightning in Stoneleigh Park during a severe storm on last Thursday week (June 24). The tree was a fine oak about forty feet high, and the lightning seemed to have struck not among the smaller branches at the top, but about two-thirds of the way up the main trunk, just where several of the larger branches came off from the stem. From this point to the ground the bark had been rent off along a strip about three inches wide, and through the whole length the wood beneath the bark had been gauged out as if by a carpenter's tool, the groove made being about an inch wide and deep. The curious fact of the tree being struck apparently among the branches at once suggested to me that the electricity must have travelled, without visible effect, through the upper branches, and only produced disruption of the wood when the current was strengthened by the combination of a great number of separate streams. I had forgotten that this was Prof. Colladon's theory of electric discharge, but am glad to be able to give it the support of this observation.

Rugby, July 3

L. Cumming

\section{Iron and Hydrogen}

IN the description given a few weeks back of the experiments of Prof. Hughes, the fact was demonstrated that iron wire in contact with dilute acids becomes brittle, and at the same time takes up hydrogen.

There are one or two points of great interest that many, perhaps, besides myself, would like to know more about.

Thus, at the same time the iron becomes brittle, does it also become harder?

This leads one to speculate on the facts illustrated in the hardening and tempering processes of steel.

We know that such liquids as water, weak acid, oil, \&c., which are used as baths in which the heated metal is quenched, are all decomposable by iron and other metals at a high temperature, the result being the liberation of hydrogen, \&c. Now is it not probable that this liberation of hydrogen is really the essential element in the physical change produced in the hardened steel ?-that is to say, that the steel absorbs, or perhaps becomes alloyed with the nascent hydrogen in contact with its surface, thus rendering it intensely hard?

Prof. Hughes has pointed out that a red heat entirely dissipates the hydrogen from the iron wire, which returns to its normal state.

This perhaps will explain the process of tempering by supposing that a certain proportion of the (hardness-rendering) hydrogen is driven off according to the temperature reached, as shown in the well-known shades of colour seen on the surface -that is to say, the hardness is proportionate to the contained hydrogen, such as that many other metals become very hard or soft by being alloyed as zinc and copper in brass, tin and copper in bronze, \&c.

This is supported by the fact that one of the most successful processes of hardening depends on the use of a quenching-bath of dilute sulphuric acid. This would be explained by the greater ease with which acidulated water is decomposed by iron, and therefore a larger bulk of the nascent hydrogen liberated on its surface could be absorbed by the metal.

The carbon in steel probably only plays the part of a gobetween in rendering the absorption of hydrogen more facile. There is a fact that also supports this, namely, if unhardened steel is dissolved in $\mathrm{HCl}$ the carbon is left in the form of graphite scales, whereas after hardening, if treated with the acid in the same manner, the residue is found to consist of a liquid hydrocarbon, thus showing the presence of hydrogen in the metal.

These points I should like to have been able to confirm or refute for myself ; but not having the required time or apparatus, I leave it with the hope that some one possessing those advan. tages will settle these questions. H. J. JoHNSTON-LAVIS

Naples

\section{"Coronella lævis"}

IN NATURE, vol. xxii, p. I 56 , the presentation is announced of two specimens of Coronella levis (British) to the Zoological Society. I have known so many persons doubt the existence of the Coronella in the New Forest that I should feel greatly obliged to any of your correspondents who would give me some information as to its history, whether it has been introduced, or is really indigenous.

H. KING

[Mr. Sclater tells us that he has no doubt that the smooth snake is indigenous to the British Islands, although it was overlooked for many years. The first living example received by the Zoological Society was in August, 1862, presented by Mr. Fenton, having been obtained in the neighbourhood of Sandhurst. Since then nearly twenty specimens have been received, chiefly from the New Forest and neighbourhood of Bournemouth. See Mr. Cooke's excellent little volume, "Our Reptiles" (London, I865), for a fall account of this species of snake. -ED.]

\section{Recall of Appearance of Books, \&c.}

I HAVE only to-day been able to read the back numbers of NATURE for the past two or three months, and hence have only now seen Mr. Ernst's letter in your issue of April 29 last.

His power of recalling the appearance of books I know is possessed by others. I have a vary large and still increasing library, but there is hardly a volume, or indeed a tract, the appearance and condition of which does not at once present itself to my mind if occasion to use it should arise. Further, being engaged in the compilation of a work some years since, wherein many references to other books were necessary, I used, 